\title{
The effect of addition of barium sulphate nanoparticles on some properties of Acetal resin
}

\begin{abstract}
Background and objective: Acetal resin or polyoxymethylene is a flexible thermoplastic radiolucent denture base material. This study aimed to evaluate the addition of barium sulfate $\mathrm{BaSO}_{4}$ nanoparticles on the mechanical and physical properties of acetal resin.
\end{abstract}

Methods: Forty two specimens were prepared from both non-modified and modified acetal resin. The tested specimens were obtained by melt extrusion into the mold equipment followed by injection molding. The radio-opacity of non-modified and modified evaluated, and then some mechanical and physical properties tested.

Results: The results of radio-opacity test showed that the radiographic density of $\mathrm{BaSO}_{4}$ $3 \%$ Acetal resin specimens was at the same level of $2 \mathrm{~mm}$ thickness of the aluminum stepwedge. Non-significant decrease noted in surface roughness, creep in all strain regions, and compressive strength and modulus of elasticity.

Conclusion: It has been concluded that the addition of $3 \% \mathrm{BaSO}_{4}$ nanoparticles produced an acceptable radio-opaque Acetal resin denture base material. Although the addition caused some changes in properties, the modified Acetal resin remained as a flexible thermoplastic material.

Keywords: Thermoplastic; BaSO4nanoparticles; Acetal resin; Radio-opaque.

\section{Introduction}

Patient needs a removable denture for the purpose of functional, psychological or financial. Construction of an esthetic removable denture with minimal display of conventional metal clasp makes a challenge to the dentist. ${ }^{1}$ Continous research in polymer science has provided "Acetal resin" (Polyoxymethylene (POM)), which is made by the polymerization of formaldehyde and is a thermoplastic technopolymer with a monomer-free crystalline structure. ${ }^{2}$ Acetal resin is a thermoplastic and injection moulded resin. It has been used as alternative denture base and denture clasp material since 1986. It was used as a clasp material due to superior aesthetics which made the clasp match the shade of the abutment tooth. ${ }^{3}$ It is very strong, resists wear and fatigue, in addition to flexiblity, which makes it the best material for pre-formed clasps of partial denture, unilateral partial denture, provisional bridges, implant abutments, occlusal splints and orthodontic appliances. ${ }^{4}$ Acetal resin and polymethyl methacrylate (PMMA) are radiolucent materials that cannot be seen using standard radiographic techniques. So in cases of accidental ingestion, aspiration traumatic impactions of the dental appliance, it is difficult to be detected and requires invasive procedures as advanced imaging techniques. Delay in localizing or removing the foreign body may be harmful to the life. ${ }^{5}$ Much research has been carried out to incorporate radio-opaque material such as metals, iodobenzene, polybarium acrylate and barium sulphate into the acrylic resin to fabricate a reasonable radio-opaque denture base material. ${ }^{6}$ The effect of radiopaque material with the $\mathrm{BaSO}_{4}$ was tested on the mechanical and physical properties of

* Department of Prosthodontics, College of Dentistry, Hawler Medical University, Erbil, Iraq. 
Acetal resin. ${ }^{7}$ Radio-opacity to X-ray tests disclosed an increase in the optical contrast as the $\mathrm{BaSO}_{4}$ concentration increases, allowing the control of the optical density. ${ }^{7}$ Thermoplastic resins have been used in dentistry for more than 50 years, the application of these materials have been increased and the demands to both the profession and public have been increased also, the materials have remarkable properties that provide excellent esthetic and biocompatible treatment options. ${ }^{8}$ Rapid Injection Systems was first proposed in 1962 by the Flexite Company. The company presented the first Flexite thermoplastic resin which was a flouropolymer (a Teflon-type of plastic). ${ }^{8}$ Acetal was first suggested as an unbreakable thermoplastic resin removable partial denture material in 1971, during this period, rapid Injection Systems established to develop the first tooth-colored clasps with a flouropolymer thermoplastic. ${ }^{9}$ In 1986, Dental ' $D$ ' reintroduced tooth colored clasps using Acetal resin. The clasp didn't need periodic adjusting to keep them tight due to clasps were flexible, and the tooth colored esthetics were treasured by the patients. Pressing Dental followed in the early 1990s with an Acetal resin under the name of "Pressing Dental" (marketed in the U.S. by DENTSPLY Company), which in addition to tooth colored clasps, has been used for a whole partial denture framework as well as other appliances such as implant abutment and orthodontic appliances. In 1992, The Flexite Company, fabricated the first pre-formed tooth color clasps known as Clasp-Eze. ${ }^{10}$

The study was carried out in attempt to modify Acetal resin flexible denture base materials. The ultimate aim was to obtain a radio-opaque Acetal resin denture base without loose of its flexibility by determining the least added concentration of $\mathrm{BaSO}_{4}$ nanoparticles, and then evaluation of some mechanical and physical properties of both non-modified and modified material.

\section{Methods}

\section{Thermoplastic injection system}

This system is composed of a flask, an electrical furnace, a heating cylinder, a metal disk and two metal cylinders, an injection unit, and an out-take tube. Acetal resins are cylindrical blocks supplied by the manufacturers in different sizes and colors (Figure 1).

\section{Mould preparation}

Metal specimens were prepared from cutting of metal steel plates by metal cutter device in same measurements as used in the tests and for each test the metal specimen fixed to a glass plate by a drop of glue. Dental stone type IV Zhermack, was used according to manufacturer's instructions poured into the lower half of the flask. Some Stone slurry placed on the metal plate to avoid trapping air when inserting the metal into the stone slurry. The glass plate inverted over the poured stone and pressed till it contacts the edges of the flask, and left to set for one hour, the glass plate then removed.

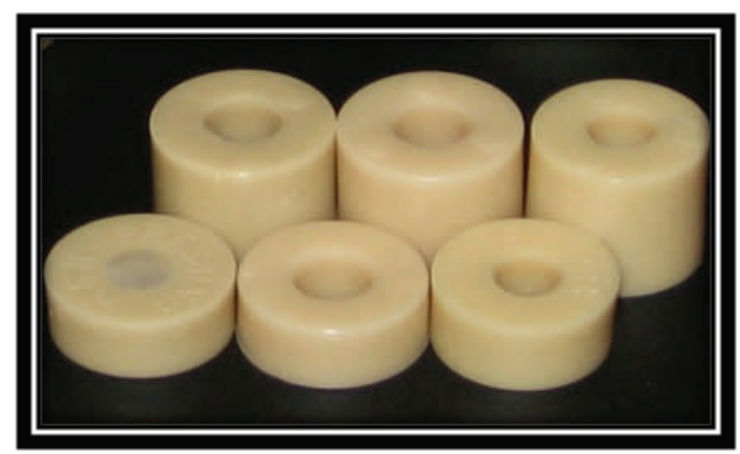

Figure 1: Acetal resin blocks in A2 color shade and different sizes. 
Wax sprues prepared before place the upper half of the flask, major sprues with 6 $-8 \mathrm{~mm}$ diameter, minor sprues $2-4 \mathrm{~mm}$ diameter, and attached to selected areas. On the other side, two other sprues attached to the specimen to act as the exit of air during injection of Acetal resin (Figure 2). The stone mould was coated with separating medium, after it dried, the upper half of the flask placed in position, the four screws of the flask tightened. The flask then placed on a vibrator and the stone poured through the hole on the top of the flask. The flask left one hour for setting the stone. After wax elimination the flask opened, the wax washed out with boiling water and cleaned with detergent. Tinfoil substitute applied on the entire stone surface. The flask placed in a dry oven Memmertat $65^{\circ} \mathrm{C}$ for 30 minutes as manufactured instruction. The two halves of the flask were tightened by the 4 screws and returned to the oven, waiting for the Acetal resin blocks to melt to be injected later on.

\section{Injecting the denture base material}

The heating cylinder inserted into the slot present in the furnace. The furnace allowed warming up to $220^{\circ} \mathrm{C}$, the heated cylinder removed. The Acetal resin cartridge, the metal disc and the short solid metal cylinder inserted into the heated cylinder and left inside the furnace for 20 minutes to allow the granules inside the cartridge to melt. The flask removed from the oven and placed inside the injection unit in vertical position in a position that the injection opening was to the top surface of the flask. The heated cylinder together with the cartridge removed from the furnace, and placed immediately on the injection opening hole of the flask and the material injected inside the flask by the manual injection unit. The handle of the injection tightened until both springs on the top side of the unit were closed. After five minutes, the flask removed from the injection unit and allowed to bench cooling at room temperature $23^{\circ} \mathrm{C}$. The flask then opened and the specimens were removed from the mould.

Preparation of radio-opaque Acetal resin specimens

\section{Pilot study}

A non-surface treated $\mathrm{BaSO}_{4}$ nano particle added to the Acetal resin renders it from radiolucent materials to radiopaque materials. For each concentration 2 specimens measured $60 \times 10 \times 2 \mathrm{~mm}$ (length, width and height) prepared by adding $\mathrm{BaSO}_{4}$ nano-particles in different percentage ratios wt/wt of $2 \%, 3 \%, 4 \%$, $5 \%, 6 \%, 7 \%, 7.5 \%$ and $10 \%$ into the Acetal resin cartridges. The cartridge shacked manually for 1 minute, to ensure a uniform distribution of $\mathrm{BaSO}_{4}$ nano powder. The cartridge placed on a vibrator horizontally for 2 minutes, with continuous manual rolling during this period, to avoid accumulation of the $\mathrm{BaSO}_{4}$ powder in the cartridges. Finally, the modified denture base material melts and injected into the previously prepared mould in the flask. The results showed that the Acetal resin

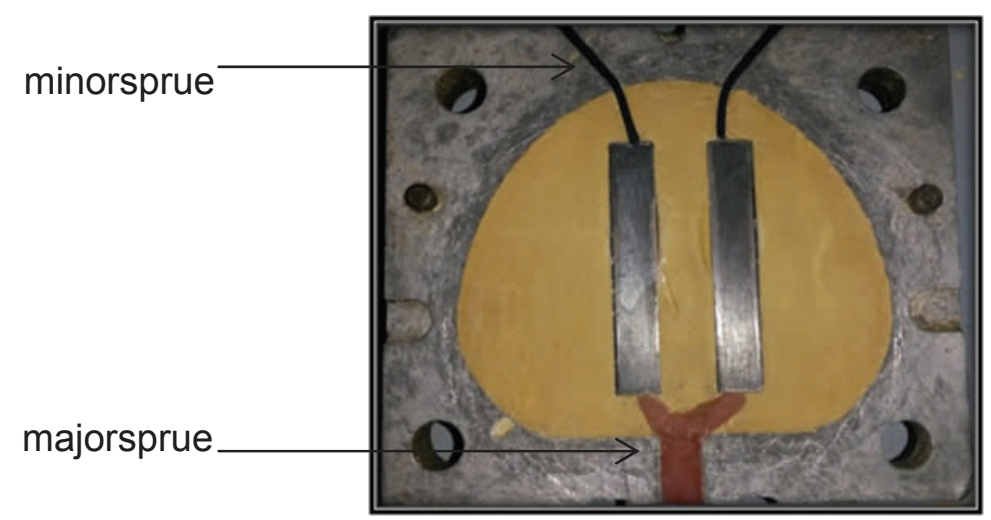

Figure 2: Metal specimens with the wax sprues in the lower half of the flask. 
specimens contained $3 \% \quad \mathrm{BaSO}_{4}$ nano particles produced adequate radiopacity at the same level of $2 \mathrm{~mm}$ thickness of the aluminum step wedge, since this ratio produced adequate radio-opacity without changing color and flexibility of the Acetal resin (Figure 3).

2. Evaluation the radio-opacity of specimens:

A chest $x$-ray was taken for the nine specimens in different concentration of $\mathrm{BaSO}_{4}$ and compared with an aluminum stepwedge; the aluminum was composed of nine steps and each step of the aluminum equal to $1 \mathrm{~mm}$ and the specimens to be equal to $2 \mathrm{~mm}$ of the aluminum as a standard for radiographic evaluation. A light transmission densitometer was to measure the difference in the image density of all specimens which contain a different concentration of $\mathrm{BaSO}_{4}$ nanoparticles in comparison with non-modified Acetal resin and aluminum step wedge. Before measuring the density of the specimens, the densitometer was preset to zero. Three measurements in different areas of each specimen were recorded, the mean of them calculated. The comparison made between the radiographic density of the specimen and the radiopacity of different thicknesses of the aluminum step wedge, to determine which thickness of the step wedge was equivalent to the specimens radiographic density (Figure 4).



Figure 3: Acetal resin specimens in different concentration

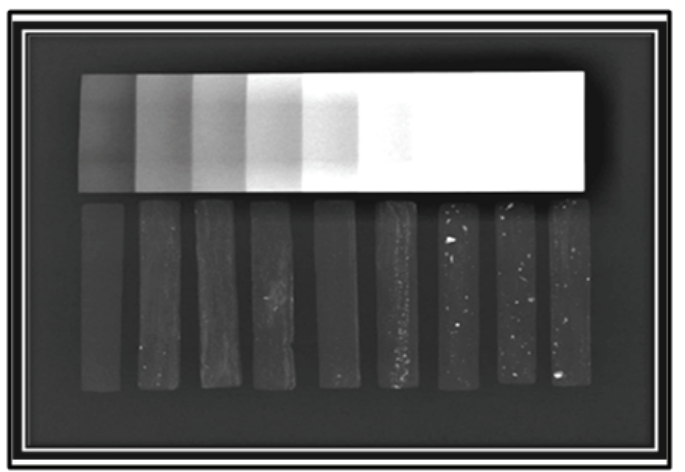

A

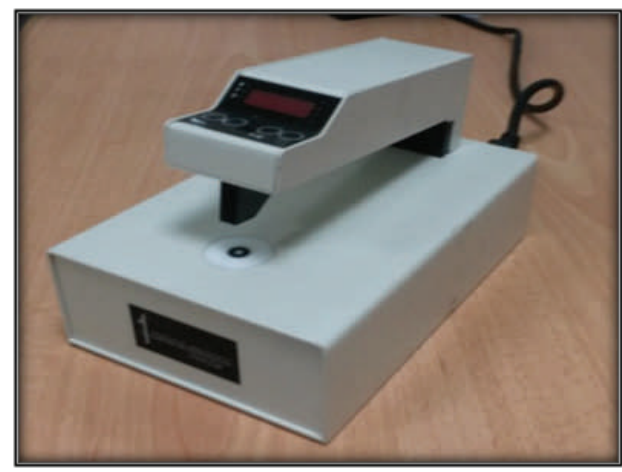

B

Figure 4: A- Radiograph of non-modified and modified specimens (From left to right: non-modified, $\% 2,3 \%, 4 \%, 5 \%, 6 \%, 7 \%, 7.5 \%$ and $10 \%$.). B-Transmission Densitometer. 
Mechanical and Physical Tests

\section{Surface roughness test:}

Fourteen rectangular specimens (seven non-modified Acetal resin and seven made of modified Acetal resin) prepared (30 ' 15 - 2.5) $\mathrm{mm}$ length, width and thickness consequently to be used for surface roughness test. This test conducted according to ISO specification no. 4287. The Profilometer device (surface roughness tester, Talysurf 4, Taylor Hobson, UK)(figure 5) used to study the micro geometry of the test surface. This device is supplied with a surface analyzer (small sharp stylus in micrometer) to trace the profile of the surface irregularities and record all the peaks and recesses which characterize the surface. The $R_{a}$ value was the arithmetic mean roughness value of the departure of the profile above and below a mean reference line. ${ }^{11}$ Average surface roughness measured at three readings and the mean was calculated. The device was formerly preset to zero.

\section{Creep test:}

The mould for this test was obtained by pouring the dumbbell-shaped flat specimens made of polyethylene with the measurements according to manufacturer's instructions which were supplied as a specimen with the creep testing machine. Then fourteen specimens of both types control and radio-opaque denture base material were prepared. The creep test was performed according to the manufacturer instructions of the creep testing machine, at room temperature $25+$ $2^{\circ} \mathrm{C}$ and without conditioning (Figure 6 ).

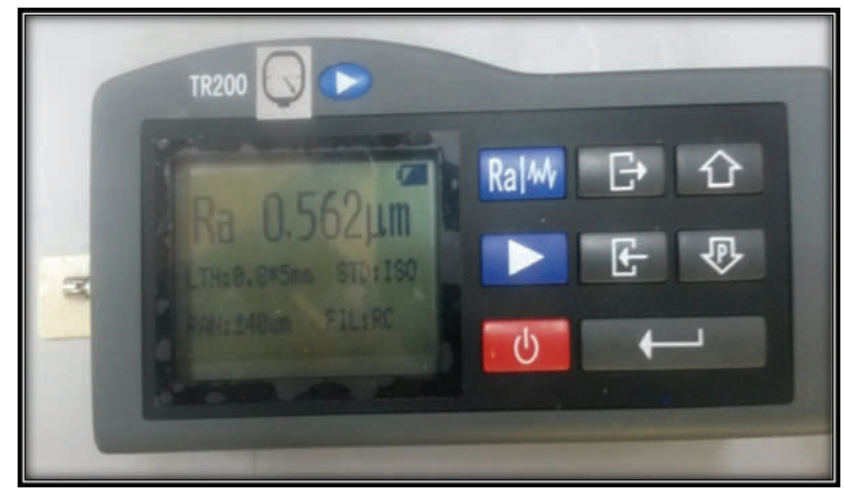

A

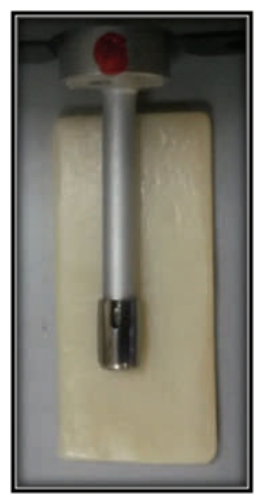

B

Figure 5: A-Profilometer device (surface roughness tester), B-Stylus tip on the specimen.

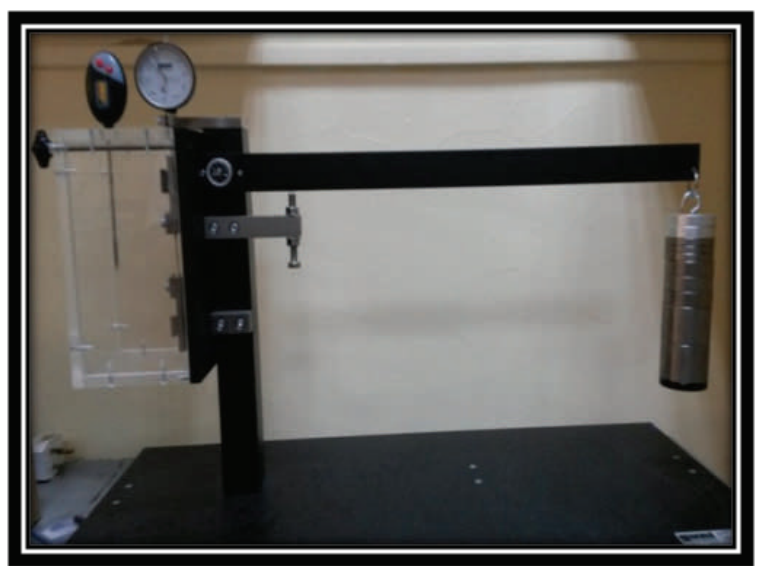

A

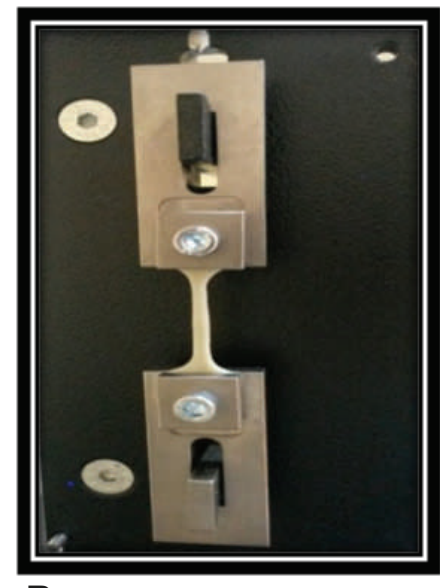

B

Figure 6: A-Creep testing machine, B-Sample hanged in the creep test. 
The specimen cross-section and lever transmission were harmonized so that the load of $1 \mathrm{~N}$ corresponds to a stress of $1 \mathrm{~N} /$ $\mathrm{mm}^{2}$ according of manufactured instruction. Prior to the application of load, the dial gauge was readjusted, the load of $20 \mathrm{~N}$ applied carefully without jolting. Then, readings at the initial phase recorded every 15 seconds (in the instant deformation and recovery phase) and at low creep rates intervals of 2, 5 minutes and then every 10 minutes. The deflection against the time continuously recorded until it reached a time where no more changes occurred, at this time the load removed and the recovery recorded at the initial phase every 15 second and at low recovery rates an intervals of 2, 5 minute and then every 10 minutes when the recovery rate was very little, since there were very little changes between two readings. The behavior of the specimen is shown in Figure 7. The amount of initial deformation, creep, the large amount of recovery, time dependent recovery, and permanent set (secondary creep) were noted.

\section{Compressive strength test:}

Fourteen cylindrical specimens (seven non -modified Acetal resin, and seven modified Acetal resin) $10 \mathrm{~mm}$ in length and $8 \mathrm{~mm}$ in diameter prepared as described by Fitton et al. in (1995). This test was done by universal testing machine WP $300.20 \mathrm{KN}$ (kilo newton) (Figure 8), The Specimens loaded by using a cross-head speed of 1.0 $\mathrm{mm} \mathrm{min}^{-1}$, the specimens subjected to the load slowly and steadily by turning the hand wheel. Application of force was stretched out over a period of 5-10 minutes without abrupt application of load in all cases. The compressive strength was reached at the moment the first crack appears then the procedure was stopped and the force that causes this crack was recorded.

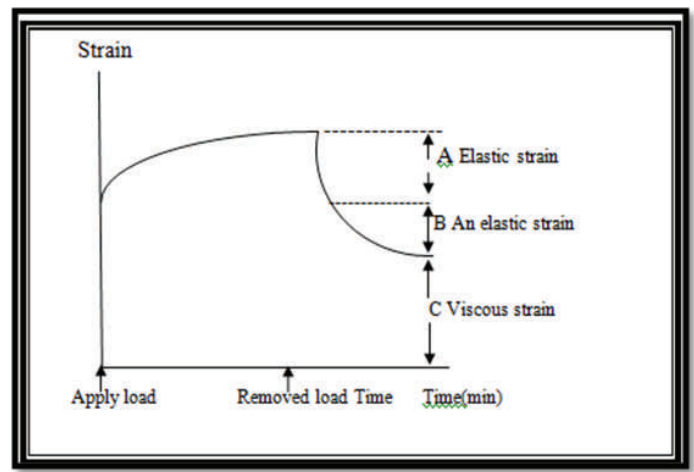

Figure 7: Creep recovery curve, showing A, elastic, B, anelastic, and C, viscous strain. ${ }^{12}$
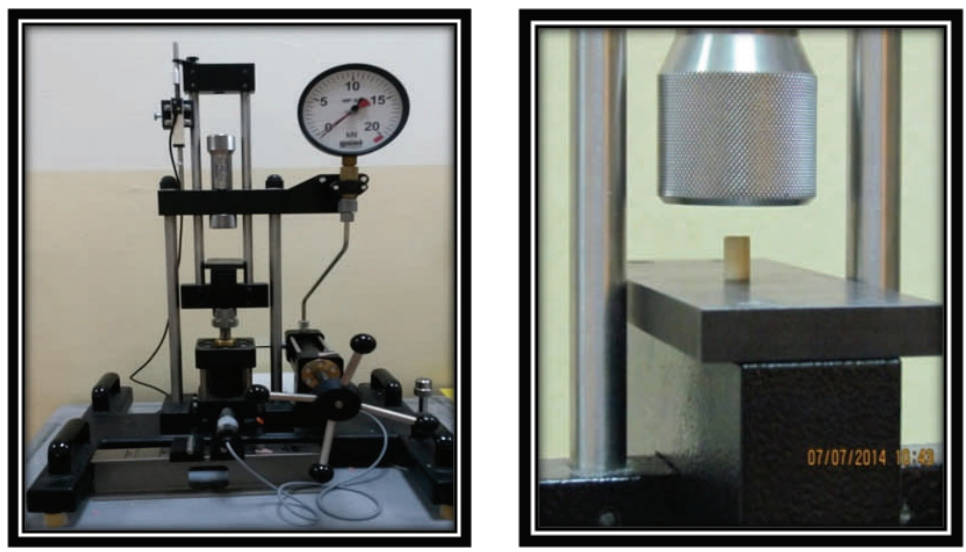

Figure 8: Universal testing machine GUNT WP $300.20 \mathrm{KN}$ for compressive strength test. 


\section{Statistical analysis}

Data were analyzed using the statistical package for the social sciences (version 19). Student t-test was carried out to determine the comparative significant difference between the specimens of two groups in non-modified and modified specimens of the Acetalresin. A $P$ value of $\leq 0.05$ was considered statistically significant.

\section{Results}

\section{Radiopacity test}

The results showed by the use of Densitometer and Aluminum stepwedge, the Acetal resin specimens contained 3\% $\mathrm{BaSO}_{4}$ nanoparticles produced adequate radiopacity at the same level of $2 \mathrm{~mm}$ thickness (second step) of the aluminum stepwedge. These ratios in all concentration of barium sulfate selected to be added to the Acetal resin specimens as shown in Table 1. Also found that the radio-opacity of Acetal resin specimens increased by a decrease in radiographic densities.

\section{Creep test}

The results showed that the mean values, standard deviation, standard error of the mean, maximum and minimum values of creep behavior in elastic, anelastic and viscous strain regions of the tested specimens are listed in the Table 2.

Table 1: Mean of Densitometer Reading of the specimens and stepwedge.

\begin{tabular}{|c|c|c|c|}
\hline \multirow{3}{*}{ Specimen } & \multicolumn{3}{|c|}{ Mean of measurements } \\
\hline & \multirow[t]{2}{*}{ Density of Specimens } & \multicolumn{2}{|c|}{ Aluminum stepwedge } \\
\hline & & Density of Aluminum & Thickness of Aluminum \\
\hline Control & 0.72 & 0.70 & $1 \mathrm{~mm}$ \\
\hline $\mathrm{BaSO}_{4} 2 \%$ & 0.70 & 0.68 & $2 \mathrm{~mm}$ \\
\hline $\mathrm{BaSO}_{4} 3 \%$ & 0.68 & 0.66 & $3 \mathrm{~mm}$ \\
\hline $\mathrm{BaSO}_{4} 4 \%$ & 0.67 & 0.64 & $4 \mathrm{~mm}$ \\
\hline $\mathrm{BaSO}_{4} 5 \%$ & 0.67 & 0.61 & $5 \mathrm{~mm}$ \\
\hline $\mathrm{BaSO}_{4} 6 \%$ & 0.66 & 0.58 & $6 \mathrm{~mm}$ \\
\hline $\mathrm{BaSO}_{4} 7 \%$ & 0.65 & 0.54 & $7 \mathrm{~mm}$ \\
\hline $\mathrm{BaSO}_{4} 7.5 \%$ & 0.65 & 0.50 & $8 \mathrm{~mm}$ \\
\hline $\mathrm{BaSO}_{4}$ 10\% & 0.64 & 0.42 & $9 \mathrm{~mm}$ \\
\hline
\end{tabular}

Table 2: Descriptive statistics and student t-test comparing the creep behavior in control and modified Acetal resin.

\begin{tabular}{lccccccc}
\hline & $\begin{array}{c}\text { Material } \\
\text { group }\end{array}$ & $\begin{array}{c}\text { Mean } \\
\mathbf{0 . 0 1} \mathbf{m m}\end{array}$ & SD & SE & $\begin{array}{c}\text { Max. } \\
\mathbf{0 . 0 1} \mathbf{m m}\end{array}$ & $\begin{array}{c}\text { Min. } \\
\mathbf{0 . 0 1} \mathbf{m m}\end{array}$ & P value \\
\hline $\begin{array}{l}\text { Creep Elastic } \\
(0.01 \mathrm{~mm})\end{array}$ & Control & 96.857 & 6.256 & 2.365 & 107 & 88 & \\
& Barium 3\% & 91.857 & 4.337 & 1.639 & 97 & 85 & 0.108 \\
$\begin{array}{l}\text { Creep anelastic } \\
(0.01 \mathrm{~mm})\end{array}$ & Control & 46.286 & 5.908 & 2.233 & 55 & 36 & \\
& Barium 3\% & 44.857 & 4.525 & 1.710 & 51 & 40 & 0.621 \\
$\begin{array}{l}\text { Creep viscous } \\
(0.01 \mathrm{~mm})\end{array}$ & Control & 23.714 & 6.184 & 2.337 & 35 & 14 & 0.879 \\
\hline \hline
\end{tabular}


The results of the mean values in all the regions of the strain (elastic, an-elastic and viscous) in the control group was 0.968 , 0.462 and $0.237 \mathrm{~mm}$, respectively, which was higher than the mean values of barium $3 \%$ group $0.918,0.448,0.232 \mathrm{~mm}$ respectively at the same regions of strain. At 0.05 level of significance, elastic, anelastic and viscous strain were not significant difference between the groups.

\section{Surface roughness test}

The results in Table 3 shows that there was no significant differences between modified and non-modified Acetal resin. However, the results showed that increasing the modified Acetal resin has lowered surface roughness $(0.991 \mu \mathrm{m})$ when compared with non-modified one $(1.005 \mu \mathrm{m})$.

Compressive strength test

The results showed that the compressive strength mean value of Acetal resin was not significant. However, the mean value of force was changed from $12.551 \mathrm{kN}$ (kilonewton) for control group to $10.096 \mathrm{kN}$ for modified group. The mean value of modulus elasticity was changed from 4.076 in control group to 3.277 in modified group, and the mean value of compressive stress was changed from $249.610 \mathrm{~Pa}$ in control group to $200.847 \mathrm{~Pa}$. This revealed that the addition of $3 \% \mathrm{BaSO}_{4}$ nanoparticles into Acetal resin that causes lowering the compressive strength, shown in Table 4.

Table 3: Descriptive statistics and t-test comparing surface roughness test in micrometer ( $\mu \mathrm{m})$.

\begin{tabular}{llcccccc}
\hline & Material Group & $\begin{array}{c}\text { Mean } \\
(\mu \mathrm{m})\end{array}$ & SD & SE & $\begin{array}{c}\text { Max. } \\
\text { value }\end{array}$ & $\begin{array}{c}\text { Min. } \\
\text { Value }\end{array}$ & $\boldsymbol{P}$ value \\
\hline $\begin{array}{l}\text { Surface } \\
\text { Roughness } \\
(\mu \mathrm{m})\end{array}$ & Control & 1.005 & 0.255 & 0.09 & 1.276 & 0.59 & 0.909 \\
\hline
\end{tabular}

Table 4: Descriptive statistics and student t-test comparing the compressive strength in control and modified Acetal resin.

\begin{tabular}{llcccccc}
\hline & $\begin{array}{l}\text { Material } \\
\text { Group }\end{array}$ & Mean & SD & SE & $\begin{array}{c}\text { Max. } \\
\text { Value }\end{array}$ & $\begin{array}{c}\text { Min. } \\
\text { value }\end{array}$ & $P$ value \\
\hline $\begin{array}{l}\text { Force }(\mathrm{F}) \\
(\mathrm{KN})\end{array}$ & Control & 12.551 & 4.719 & 1.784 & 19.412 & 6.90 & \\
& Barium3\% & 10.096 & 3.245 & 1.227 & 15.851 & 5.71 & 0.279 \\
& Control & 4.076 & 1.564 & .591 & 7.151 & 2.49 & \\
$\begin{array}{l}\text { Modulus } \\
\text { of elasticity }\end{array}$ & Barium3\% & 3.277 & .622 & .235 & 4.32 & 2.73 & \\
& Control & 249.610 & 93.864 & 35.477 & 386.189 & 137.39 & \\
$\begin{array}{l}\text { Compressive } \\
\text { strength, (pa) }\end{array}$ & Barium3\% & 200.847 & 64.565 & 24.403 & 315.344 & 113.66 & \\
\hline
\end{tabular}




\section{Discussion}

\section{Radiopacity Test}

Acetal resin is a radiolucent material. Accidental inhaling or ingesting dentures might cause a suffocation and death of the patient if the inhaling material could not be seen in the radiograph. Therefore, the production of a radiopaque denture base material became a subject of most important for many researchers. In the present study, extra-oral radiographs were used as it is more commonly used for emergency cases as a diagnostic mean. An aluminum stepwedge was used to standardize the densities of the exposed films. $\mathrm{BaSO}_{4}$ nanoparticles tend to fill any pores or air bubbles that might incorporate into the Acetal resin during adding, and the light is not transmitted into the particles within the translucent Acetal resin and causes an increase in radio-opacity of the material.Acetal resin modified by the addition of $3 \% \quad \mathrm{BaSO}_{4}$ nanoparticles showed radiopacity similar to the second step of the stepwedge. After the addition of $\mathrm{BaSO}_{4}$ powder the transmission densitometer showed a reduction in the radiographic density, while the control group showed the highest mean of radiographic density (lower radio-opacity). Similar findings were also obtained by Hasan in (2009) when he used 15\% of micro sized $\mathrm{BaSO}_{4}$ particles. ${ }^{12}$ The increase in radiopacity is due to the presence of the radiopaque $\mathrm{BaSO}_{4}$ powder in the polymer matrix which absorbs more radiation than polymer matrix and appears more radiopaque, and may be related to the high atomic number of $\mathrm{BaSO}_{4}$ compared to the chemical constituent of the Acetal resin which has low atomic number and since the barium atom is large and heavy, it absorbs X-rays relatively well.

\section{Surface roughness}

The slight decrease of the surface roughness of the modified specimens may be due to the presence of the $\mathrm{BaSO}_{4}$ nanopowders at the surface which acts as fillers among the interpolymeric chains and fills the voids in the body of the specimens.
Also, this may be due to of finishing and polishing of the specimens. The changes of the surface roughness agreed with Ihab and Moudhaffar (2011) since they found that the addition of nano-ZrO2 fillers into the acrylic denture base did not significantly change the surface roughness when different percentages of modified acrylic denture base material. But the results of the current study is in disagreement with the findings of Vojdani et al (2012) who concluded that incorporation of micron-sized $\mathrm{Al}_{2} \mathrm{O}_{3}$ powder in the heat cured acrylic resin produced a slight increase in the surface roughness. This may be due to the fillers used which are different from the fillers in the present study.

\section{Creep}

Creep is a time dependent deformation produced by stress, in a completely set material. ${ }^{13}$ Deformation that occurs over a period of time when a material is subjected to constant stress at a constant temperature. The addition of $\mathrm{BaSO}_{4}$ to the non-modified Acetal resin denture base material caused decreasing in the time dependant displacements in all the three regions elastic, an-elastic and viscous. The differences between the reductions of the displacement were not significant for elastic, an-elastic and viscous regions. The addition of $\mathrm{BaSO}_{4}$ causing lowering of the mean of time dependent displacement of modified when compared with nonmodified specimens from the elastic region, inelastic region and in the viscous region due to the decrease of elasticity and flexibility. The result agreed with Sehajpal and Sood (1989), were studied that the lowering of the displacements of all regions in creep behavior, it was due to the presence of $\mathrm{BaSO}_{4}$ fillers inside the nylon matrix may be due to the voids which resulting from entrapped air and moisture also reduce tensile strength because there is incomplete wetting of fillers by the resin, when they stated that a decrease in the cross section of load-bearing polymer matrix, stress concentration because of 
filler particles change in the modulus of elasticity of composite resin, and mode of crack propagation through it because of filler. Moreover, the even dispersion of low concentration of the nanoparticles may be because the magnitude of $\mathrm{BaSO}_{4}$ aggregation increases with increasing $\mathrm{BaSO}_{4}$ loading. This perhaps due to the effect of the attraction forces between the nanoparticles themselves. Also because of the high adsorption surface energies associated with these nano fillers caused them to have a strong tendency to form agglomerates and aggregates (Romero-lbarra et al., 2012). The result agreed with Hasan (2009) when he used $15 \% \quad \mathrm{BaSO}_{4}$ micropartices into Valplast nylon denture bases was lower for the elastic, anelastic and viscous regions when compared to the control group.

\section{Compressive strength test}

The addition of $3 \% \mathrm{BaSO}_{4}$ nanoparticles into Acetal resin caused non-significant differences in force, modulus of elasticity and compressive strength. The decrease in the compressive strength may be due to the addition of $\mathrm{BaSO}_{4}$ nano-particles results in the formation of foci and aggregates of the powder into the polymer which is due to the breakdown of the interface of the bond between the filler and resin matrix. When there is a breakdown of this interface, the stress developed under load will not be effectively distributed throughout the material. ${ }^{6}$ It is also perhaps due to voids in the center of cylindrical specimens, and edge defects. ${ }^{2}$ The very low modulus of elasticity indicates a high degree of flexibility. The low modulus of elasticity of the modified Acetal resin means that the addition of $\mathrm{BaSO}_{4}$ did not affect the flexibility of the composite. These findings are in agreement with Fitton et al. ${ }^{2}$ that the examination of POM failure characteristics, shows that Acetal resin whilst having a relatively low elastic modulus in flexure is, in fact, an extremely tough material. Although the sample suffered permanent deformation, it did not break at the maximum applied force. This implies that clinically a denture component made from Acetal resin would be very resistant to fracture from high levels of force.

\section{Conclusion}

The addition of $3 \% \mathrm{wt} / \mathrm{wt} \mathrm{BaSO}_{4}$ nano particle produced an acceptable radio-opaque thermoplastic Acetal resin. Although there were slight changes in properties of the modified specimens, it remained as flexible denture material and can be used in the patient's mouth without any detrimental effects.

\section{Conflicts of interest}

The authors report no conflicts of interest.

\section{References}

1. Lekha K, Savitha NP, Meshramkar R, Ramesh $\mathrm{KN}$. Acetalresin as an esthetic clasp material. J Interdisciplinary Dentistry 2012; 2(1):11-4.

2. Fitton JS, Davies EH, Howlett JA, Pearson GJ. The physical properties of a polyacetal denture resin. J Clin Mater 1995; 17:125-9.

3. Turner JW, Radford DR, Sherriff M. Flexural properties and surface finishing of acetal resin denture clasps. J Prosthodont 1999; 8:188-95.

4. Phoenix RD, Mansueto MA, Ackerman NA, Jones RE. Evaluation of mechanical and thermal properties of commonly used denture base resins. J Prosthodont 2004; 13:17-27.

5. Mattie PA, Rawls HR, Cabasso I. Development of a radio-opaque auto polymerizing dental acrylic resin. J Prosthodontic 1994; 3:213-8.

6. Combe EC. Further studies on radio-opaque denture base materials. J Dent 1972; 1:93-7.

7. Romero-lbarra IC, Bonilla-Blancas E, SánchezSolís A, Manero O. Influence of X-ray opaque $\mathrm{BaSo}_{4}$ nanoparticles on mechanical, thermal and rheological properties of polyoxymethylene nano composites. J Polymer Engeneer 2012; 32:319-26.

8. Beaumont AJ. An overview of esthetics with removable partial dentures. Quintessence Int 2002; 33(10):747-55.

9. Donovan TE, Cho GC. Esthetic considerations with removable partial dentures. J Calif Dent Assoc 2003; 31(7):551-7.

10. Kutsch VK, Whitehouse JW, Schermerhorn K. The evolution and advancement of dental thermoplastics. J Dental Town 2003; 4(2):52-6.

11. Hareri GI. Surface finish improvement in metal hard turning and burnishing operation. Ph.D. Thesis. University of Salahaddin, College of Engineering. Iraq; 2005. 
The effect of addition of barium sulphate .......

Zanco J. Med. Sci., Vol. 21, No. (3), December, 2017

https://doi.org/10.15218/zjms.2017.039

12. Hasan RM. The effect of addition of radiopaque materials on some mechanical and physical properties of flexible denture base. Ph.D. Thesis. Hawler Medical University. College of Dentistry. Iraq; 2009.

13. Soratur SH. Essentials of dental materials. $1^{\text {st }}$ ed. New Delhi, India: Jaypee; 2002. p. 69. 